\title{
Modeling of Characteristics on Artificial Intelligence IQ Test: a Fuzzy Cognitive Map-Based Dynamic Scenario Analysis
}

\author{
F. Liu, Y. Peng, Z.X. Chen, Y. Shi
}

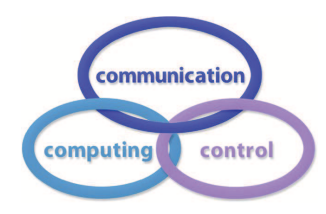

\section{Fangyao Liu*}

Department of Information Systems and Quantitative Analysis University of Nebraska at Omaha, Omaha, NE, 68182, USA

*Corresponding author: fangyaoliu@unomaha.edu

\section{Yayu Peng}

Department of Electrical and Computer Engineering

University of Nebraska-Lincoln, Lincoln, NE, 68588, USA

yayu.peng@huskers.unl.edu

\section{Zhengxin Chen}

Department of Computer Science

University of Nebraska at Omaha, Omaha, NE, 68182, USA

zchen@unomaha.edu

\section{Yong Shi}

1. Department of Information Systems and Quantitative Analysis

University of Nebraska at Omaha, Omaha, NE, 68182, USA

2. Key Lab of Big Data Mining and Knowledge Management, China Academy of Sciences, Beijing, 100190, China

yshi@unomaha.edu

\begin{abstract}
This research article uses a Fuzzy Cognitive Map (FCM) approach to improve an earlier proposed IQ test characteristics of Artificial Intelligence (AI) systems. The defuzzification process makes use of fuzzy logic and the triangular membership function along with linguistic term analyses. Each edge of the proposed FCM is assigned to a positive or negative influence type associated with a quantitative weight. All the weights are based on the defuzzified value in the defuzzification results. This research also leverages a dynamic scenario analysis to investigate the interrelationships between driver concepts and other concepts. Worst and best-case scenarios have been conducted on the correlation among concepts. We also use an inference simulation to examine the concepts importance order and the FCM convergence status. The analysis results not only examine the FCM complexity, but also draws insightful conclusions.

Keywords: fuzzy cognitive Map (FCM), inference simulation, artificial intelligent system, dynamic scenario analysis, IQ Test, linguistic analysis.
\end{abstract}

\section{Introduction}

In the academic field, artificial intelligence (AI) is a popular topic. And, many scholar papers and projects focused on this topic $[7,33,36]$. Also, in industry field, AI-based products are trying to make our lives more convenient and efficient [7]. However, there is a warm debate about 
whether the emerging AI systems have the potential of helping or doing something devastating to human. To evaluate the smartness of AI systems, Liu et al. paper presents a method to measure the AI system through an IQ test [23]. Based on its measurement framework, a list of 100 AI-based search engines received an IQ score. For example, based on the IQ test result, Google search engine got the highest IQ score of 47.28 [23]. Which means Google's IQ score is almost the same as a six-year-old child's IQ score. These IQ results illustrate that AI-based system still has a long way to go to replace human, at least in industry world.

For the purpose of successfully conducting the IQ test for all the top 100 search engines, such as Google, Bing, Baidu, etc. In 2015, Liu et al. [23] proposed a measurement framework. This framework includes a test bank, which has hundreds of questions. Like a human IQ test, each search engine need to answer several questions that are selected from the developed test bank by random. For each question, they will receive a score between 0 and 100. This framework divides all the questions into four main indicator groups and further into 15 characteristics. Also, a few adult volunteers had the IQ test for the purpose of standardizing the IQ score, and mapping with the human being's IQ score.

Table 1 lists all the 15 IQ characteristics along with their corresponding weights for testing AI systems. After gathering expert opinions (Delphi method), all the 15 weights are calculated and presented in the Table 1.

- $\mathrm{C} 1 \mathrm{~m}(\mathrm{~m}=1,2 \ldots \mathrm{m})=$ ability to acquire knowledge.

- $\mathrm{C} 2 \mathrm{n}(\mathrm{n}=1,2 \ldots \mathrm{n})=$ ability to master knowledge.

- C3p $(\mathrm{p}=1,2 \ldots \mathrm{p})=$ ability to innovate knowledge.

- $\mathrm{C} 4 \mathrm{q}(\mathrm{q}=1,2 \ldots \mathrm{q})=$ ability of knowledge feedback.

Table 1: 15 IQ Characteristics for AI system and their corresponding Delphi weights

\begin{tabular}{|l|l|l|l|}
\hline C1m & C2n & C3p & C4q \\
\hline $\begin{array}{l}\text { C11: Ability to identify } \\
\text { word (3\%) }\end{array}$ & $\begin{array}{l}\text { C21: Ability to master gen- } \\
\text { eral knowledge }(6 \%)\end{array}$ & $\begin{array}{l}\text { C31: Ability to innovate by } \\
\text { association (12\%) }\end{array}$ & $\begin{array}{l}\text { C41: Word feedback ability } \\
(3 \%)\end{array}$ \\
\hline $\begin{array}{l}\text { C12: Ability to identify } \\
\text { sound (3\%) }\end{array}$ & $\begin{array}{l}\text { C22: Ability to master } \\
\text { translation (3\%) }\end{array}$ & $\begin{array}{l}\text { C32: Ability to innovate by } \\
\text { creation (12\%) }\end{array}$ & $\begin{array}{l}\text { C42: Sound feedback abil- } \\
\text { ity (3\%) }\end{array}$ \\
\hline $\begin{array}{l}\text { C13: Ability to identify im- } \\
\text { age (4\%) }\end{array}$ & $\begin{array}{l}\text { C23: Ability to master cal- } \\
\text { culation (6\%) }\end{array}$ & $\begin{array}{l}\text { C33: Ability to innovate by } \\
\text { speculation (12\%) }\end{array}$ & $\begin{array}{l}\text { C43: Image feedback abil- } \\
\text { ity (4\%) }\end{array}$ \\
\hline & $\begin{array}{l}\text { C24: Ability to master ar- } \\
\text { rangement(5\%) }\end{array}$ & $\begin{array}{l}\text { C34: Ability to innovate by } \\
\text { selection (12\%) }\end{array}$ \\
\hline & & $\begin{array}{l}\text { C35: Ability to innovate by } \\
\text { discover laws }(12 \%)\end{array}$ & \\
\hline & &
\end{tabular}

The proposed IQ test question bank is arranged according to all the 15 IQ characteristics (concepts). To illustrate, an example of testing question: "Please translate 'Technology's impact' into Spanish" should belong to characteristic C22 (Ability to master translation).

The results of Delphi weights are very subjective. Because they are coming from expert's own judgment, which means the results may be biased. Take advantage of linguistic terms from literature sources can be treated as a better method because all the literature publication sources are considered as an objective approach. One of the article's goals is to assign new weights though the fuzzy logic method (an objective approach). Based on the new weights, the interrelations among characteristics also should be investigated. There are some significant relationships among some characteristics. For example, "C21: Ability to master general knowledge" literally has a positive impact on "C24: Ability to master arrangement".

The main method of this research article is a fuzzy logic mathematics method, more specifically, called "fuzzy cognitive mapping" or "fuzzy cognitive map" (FCM). The core idea behind 
fuzzy logic is that it aims to model the more imprecise reasoning used by humans when they make rational decisions, especially in an uncertain and imprecise environment [14,37]. By providing a mathematical means of representing vagueness, fuzzy logic models, or sets, are able to recognize, represent, manipulate interdependence between characteristics (concepts).

\section{Research method}

\subsection{Methodology}

Fuzzy Cognitive Mapping (FCM) is the most important method of this research article. For the purpose of constructing FCM, the number of edges should be clarified. Theoretically, all the combination of two concepts should have an edge (relationship). However, the literature resources only support the meaningful edges, for example, the edge between one IQ characteristic and the AI system, or the edges of the interrelations among the 15 IQ characteristics. According to the literature resources, it is easy to assign the influence type (negative, positive, or null) of the edge.

Keyword extraction plays a significant role in the relationship between concepts capturing. For instance, one reference paper said concept C22 heavily impacts concept C31, then, keyword "heavily impacts" will be extracted here. Each keyword will be assigned with one of the linguistic terms ("VERY LOW", "LOW", "MEDIUM", "HIGH", and "VERY HIGH"). At least three linguistic terms will be assigned to each edge.

The linguistic terms are fuzzy set problems. The membership function plays a significant role in quantifying the membership grade of the element in $\mathrm{X}$ to the fuzzy set [45].

$$
\mu_{A}: X \rightarrow[0,1]
$$

Where $X$ represents the universe of discourse while the fuzzy set is $A$, and $\mu_{A}$ is the membership function [8].

A triangular function will be used in the FCM constructing process. Where $a$ is the lower limit, $b$ is the upper limit, and $m$ is a value between $a$ and $b$. Figure 1 illustrates the membership function as a graph.

$$
\mu_{A}=\left\{\begin{array}{cc}
0, & x \leq a \\
\frac{x-a}{m-a}, & a<x \leq m \\
\frac{b-x}{b-m}, & m<x \leq b \\
0, & x>b
\end{array}\right.
$$

\section{$2.2 \quad$ Linguistic term analyses}

The literature resources, support the linguistic term assigning as references. Table 2 summarizes all the possible relationships between each IQ characteristic and the AI system, and the interrelationship among the 15 IQ characteristics. In particular, Barwise's paper mentioned IQ characteristics' ability to identify word is a "most common view" of AI system [24]. Then, the keyword "most common view" will be extracted here, while a linguistic term "HIGH" will be assigned to this edge. Table 2 gives an outline of the linguistic terms, influence type, keywords, and their corresponding reference papers.

In Table 2, "C" represents the "AI system IQ". 


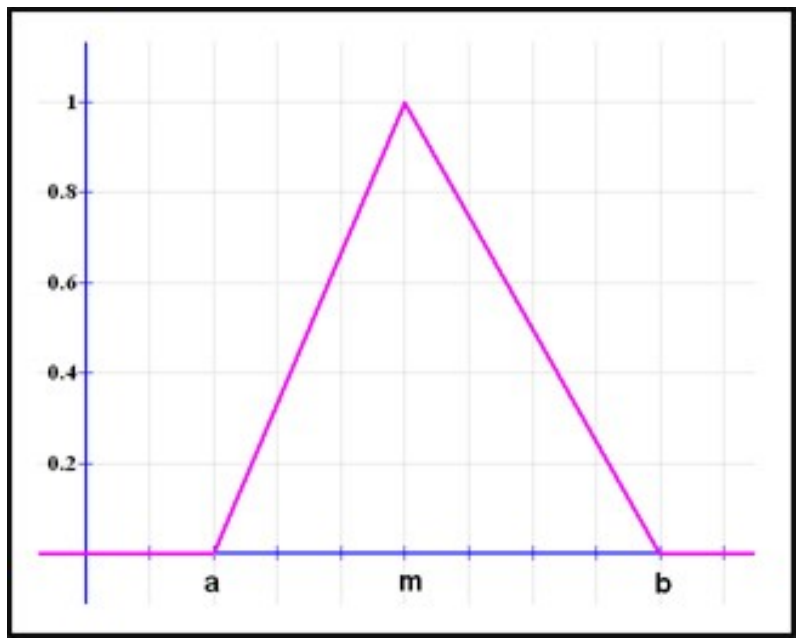

Figure 1: Membership function graph [19]

Table 2: Linguistic terms and their associated references

\begin{tabular}{|c|c|c|c|}
\hline $\begin{array}{l}\text { EDGE } \\
\text { OF } \\
\text { FCM }\end{array}$ & KEYWORD & $\begin{array}{l}\text { LINGUISTIC } \\
\text { TERM }\end{array}$ & REFERENCE \\
\hline \multirow{3}{*}{$\mathrm{C} 11-\mathrm{C}$} & an aspect of & LOW & Lynn et al (2001) [24] \\
\hline & an aspect of & LOW & Lynn et al (2001) [24] \\
\hline & an aspect of & LOW & Lynn et al (2001) [24] \\
\hline \multirow{3}{*}{$\mathrm{C} 12-\mathrm{C}$} & a key strategic & HIGH & Francisco (2015) [24] \\
\hline & core capabilities & HIGH & Bernard (2018) [24] \\
\hline & obvious & LOW & Adam (2016) [24] \\
\hline \multirow{2}{*}{$\mathrm{C} 13-\mathrm{C}$} & core capabilities & HIGH & Bernard (2018) [24] \\
\hline & enable & MEDIUM & Flatworld (2017) [24] \\
\hline \multirow{4}{*}{$\mathrm{C} 21-\mathrm{C}$} & important component & HIGH & Bates et al (2003) [24] \\
\hline & correlated & MEDIUM & Chamorro-Premuzic et al (2006) [24] \\
\hline & partly represented & LOW & Cattell (1987) [24] \\
\hline & related to & MEDIUM & Ackerman (2001) [24] \\
\hline \multirow{3}{*}{$\mathrm{C} 22-\mathrm{C}$} & no significant correlation & VERY LOW & Moghimi et al (2013) [24] \\
\hline & week relationship & LOW & Nasimi (2009) [24] \\
\hline & no interrelationship & VERY LOW & Shangarffam (2009) [24] \\
\hline \multirow{3}{*}{$\mathrm{C} 23-\mathrm{C}$} & intersection & LOW & Greenberg (2000) [24] \\
\hline & accelerate & MEDIUM & Greenberg (2000) [24] \\
\hline & interleave & MEDIUM & Greenberg (2000) [24] \\
\hline \multirow{2}{*}{$\mathrm{C} 24-\mathrm{C}$} & a significant & MEDIUM & Wechsler, D. (1949) [24] \\
\hline & common view & MEDIUM & APA (1995) [24] \\
\hline \multirow{3}{*}{ C31-C } & interpreted to & MEDIUM & Singh-Manoux et al (2005) [24] \\
\hline & display & MEDIUM & Schutte et al (2011) [24] \\
\hline & measures of & HIGH & Ferguson et al (2010) [24] \\
\hline \multirow{3}{*}{$\mathrm{C} 32-\mathrm{C}$} & demonstrates & HIGH & Kim et al (2010) [24] \\
\hline & must entail & VERY HIGH & Gardner et al (1996) [24] \\
\hline & referred to & HIGH & Sternberg (1985) [24] \\
\hline & been central to & VERY HIGH & James (1950) [24] \\
\hline
\end{tabular}

C33-C 
Modeling of Characteristics on Artificial Intelligence IQ Test:

a Fuzzy Cognitive Map-Based Dynamic Scenario Analysis

\begin{tabular}{|c|c|c|c|}
\hline & fundamental to & VERY HIGH & Leighton et al (2004) [24] \\
\hline & can be important & HIGH & Bruner (1957) [24] \\
\hline \multirow{3}{*}{ C34-C } & directly & MEDIUM & Sternberg (1981) [24] \\
\hline & commonly used & MEDIUM & Mayer et al (2007) [24] \\
\hline & connects to & MEDIUM & Brackett et al (2006) [24] \\
\hline \multirow{2}{*}{$\mathrm{C} 35-\mathrm{C}$} & related to & MEDIUM & Teuber et al (1956) [24] \\
\hline & may affect & LOW & Carroll (1993) [24] \\
\hline \multirow{3}{*}{$\mathrm{C} 41-\mathrm{C}$} & are as likely to & LOW & Argyris (1991) [24] \\
\hline & important element & MEDIUM & Abisamra (2000) [24] \\
\hline & a key for & HIGH & Jorfi et al (2014) [24] \\
\hline \multirow{3}{*}{$\mathrm{C} 42-\mathrm{C}$} & linked to & LOW & Luwel (2013) [24] \\
\hline & taken into consideration & MEDIUM & FernÅAzndez-MartÅnez (2012) [24] \\
\hline & is important to & HIGH & Bohland (2010) [24] \\
\hline \multirow{3}{*}{$\mathrm{C} 43-\mathrm{C}$} & dominated by & HIGH & Barry (1997) [24] \\
\hline & driven by & MEDIUM & Messaris (1994) [24] \\
\hline & result in & HIGH & Roth et al (2005) [24] \\
\hline \multirow{3}{*}{$\mathrm{C} 11-\mathrm{C} 12$} & statistically significant & MEDIUM & Stanovich et al (1978) [39] \\
\hline & foundational & VERY HIGH & Stanovich (1991) [40] \\
\hline & strong connected & VERY HIGH & Nation et al (1998) [30] \\
\hline \multirow{3}{*}{$\mathrm{C} 11-\mathrm{C} 13$} & improve & MEDIUM & Hull (1994) [17] \\
\hline & dependent & MEDIUM & Zhu et al (2001) [44] \\
\hline & benefit & MEDIUM & Wang et al (2001) [43] \\
\hline \multirow{3}{*}{$\mathrm{C} 21-\mathrm{C} 22$} & important & MEDIUM & Collombat (2006) [9] \\
\hline & widely identified as & LOW & Collombat (2006) [9] \\
\hline & never an empty mind of & MEDIUM & Delisle (2003) [13] \\
\hline \multirow{3}{*}{$\mathrm{C} 21-\mathrm{C} 23$} & result from & HIGH & Baroody (1999) [5] \\
\hline & partially predicted by & LOW & Cowan (2011) [10] \\
\hline & as the basis & MEDIUM & Askew (1998) [4] \\
\hline \multirow{3}{*}{$\mathrm{C} 21-\mathrm{C} 24$} & commonly used & MEDIUM & Rugg et al (1997) [35] \\
\hline & spontaneously & MEDIUM & Mandler et al (1988) [28] \\
\hline & related to & MEDIUM & Gopnik et al (1984) [16] \\
\hline \multirow{3}{*}{ C21-C31 } & able to & MEDIUM & Feigenson et al (2004) [15] \\
\hline & a key precursor of & VERY HIGH & De Smedt et al (2009) [11] \\
\hline & access to & HIGH & De Smedt et al (2011) [12] \\
\hline \multirow{3}{*}{ C21-C32 } & according to & MEDIUM & Afuah et al (2003) [1] \\
\hline & used to & MEDIUM & Afuah et al (2003) [1] \\
\hline & embodied in & HIGH & Talaya et al (2008) [41] \\
\hline \multirow{3}{*}{ C21-C33 } & found to be & HIGH & Scardamalia et al (1992) [38] \\
\hline & directive effect & MEDIUM & Miyake et al (1979) [29] \\
\hline & prompted by & HIGH & Bereiter (1989) [6] \\
\hline \multirow{3}{*}{ C21-C34 } & facilitate & HIGH & Alexander et al (1995) [3] \\
\hline & related to & MEDIUM & Qian et al (1995) [34] \\
\hline & as a basic & MEDIUM & Linnenbrink-Garcia et al (2012) [22] \\
\hline \multirow{3}{*}{ C21-C35 } & needed for & MEDIUM & Njoo et al (1993) [31] \\
\hline & lies in & HIGH & Klahr et al (1988) [18] \\
\hline & support & HIGH & Van (1988) [42] \\
\hline \multirow[b]{2}{*}{$\mathrm{C} 41-\mathrm{C} 42$} & statistically significant & MEDIUM & Stanovich (1978) [39] \\
\hline & foundational & VERY HIGH & Stanovich (1991) [40] \\
\hline
\end{tabular}




\begin{tabular}{|l|c|l|c|} 
& strong connected & VERY HIGH & Nation et al (1998) [30] \\
\hline \multirow{3}{*}{ C41-C43 } & improve & MEDIUM & Hull (1994) [17] \\
\cline { 2 - 4 } & dependent & MEDIUM & Zhu et al (2001) [44] \\
\cline { 2 - 4 } & benefit & MEDIUM & Wang et al (2011) [43] \\
\hline \multirow{3}{*}{ C31-C35 } & valuable for & MEDIUM & Agrawal et al (1996) [2] \\
\cline { 2 - 4 } & led to & HIGH & Piatetsky-Shapiro (1996) [32] \\
\cline { 2 - 4 } & indicate & HIGH & Koperski (1995) [20] \\
\hline \multirow{3}{*}{ C31-C32 } & representative & HIGH & Luhn (1958) [25] \\
\cline { 2 - 4 } & based on & MEDIUM & Luhn $(1958)[25]$ \\
\cline { 2 - 4 } & significance & MEDIUM & Luhn (1958) [25] \\
\hline
\end{tabular}

Based on the extracted keyword results, Table 3 is a more advanced tabulation is used to summary keyword information into a table according to their linguistic terms.

Table 3: Categorization of keywords based on linguistic terms

\begin{tabular}{|c|c|c|c|}
\hline LINGUISTIC TERM & & KEYWORD & \\
\hline VERY LOW & no significant correlation & no interrelationship & \\
\hline LOW & $\begin{array}{l}\text { an aspect of } \\
\text { obvious } \\
\text { partly represented } \\
\text { partially predicted by }\end{array}$ & $\begin{array}{l}\text { week relationship } \\
\text { intersection } \\
\text { widely identified as }\end{array}$ & $\begin{array}{l}\text { are as likely to } \\
\text { linked to } \\
\text { may affect }\end{array}$ \\
\hline MEDIUM & $\begin{array}{l}\text { a field of } \\
\text { enable } \\
\text { taken into consideration } \\
\text { according to } \\
\text { needed for } \\
\text { connects to } \\
\text { directly } \\
\text { commonly used } \\
\text { directive effect } \\
\text { related to } \\
\text { as a basic } \\
\text { improve }\end{array}$ & $\begin{array}{l}\text { accelerate } \\
\text { important } \\
\text { never an empty mind of } \\
\text { as the basis } \\
\text { spontaneously } \\
\text { able to } \\
\text { used to } \\
\text { correlated } \\
\text { a significant } \\
\text { common view } \\
\text { interpreted to }\end{array}$ & $\begin{array}{l}\text { important element } \\
\text { display } \\
\text { statistically significant } \\
\text { dependent } \\
\text { benefit } \\
\text { valuable for } \\
\text { based on } \\
\text { significance } \\
\text { interleave } \\
\text { driven by }\end{array}$ \\
\hline $\mathrm{HIGH}$ & $\begin{array}{l}\text { prompted by } \\
\text { most common view } \\
\text { facilitate } \\
\text { lies in } \\
\text { support } \\
\text { led to } \\
\text { important } \\
\text { result in }\end{array}$ & $\begin{array}{l}\text { a key for } \\
\text { dominated by } \\
\text { result from } \\
\text { referred to } \\
\text { access to } \\
\text { core capabilities } \\
\text { embodied in } \\
\text { representative }\end{array}$ & $\begin{array}{l}\text { demonstrates } \\
\text { can be important } \\
\text { a key strategic } \\
\text { component } \\
\text { measures of } \\
\text { indicate } \\
\text { found to be }\end{array}$ \\
\hline VERY HIGH & $\begin{array}{l}\text { must entail } \\
\text { been central to }\end{array}$ & $\begin{array}{l}\text { strong connected } \\
\text { a key precursor of }\end{array}$ & foundational \\
\hline
\end{tabular}

\subsection{Defuzzification method}

Table 2 and Table 3, present a tabulation of the defined five linguistic terms in the fuzzy set we will use later. The Triangular Membership Function [19] which is shown in Figure 2 means different linguistic terms have different output values.

For the purpose of converting a fuzzified output values into a traditional single crisp value, defuzzification process will be used here [27]. Among the existing defuzzification approaches (COG, COA, BOA, etc.), in this research article, we use the Center of Sums (COS) approach, which is one very useful approach for the defuzzification process [14,27]. This equation of COS is below: 


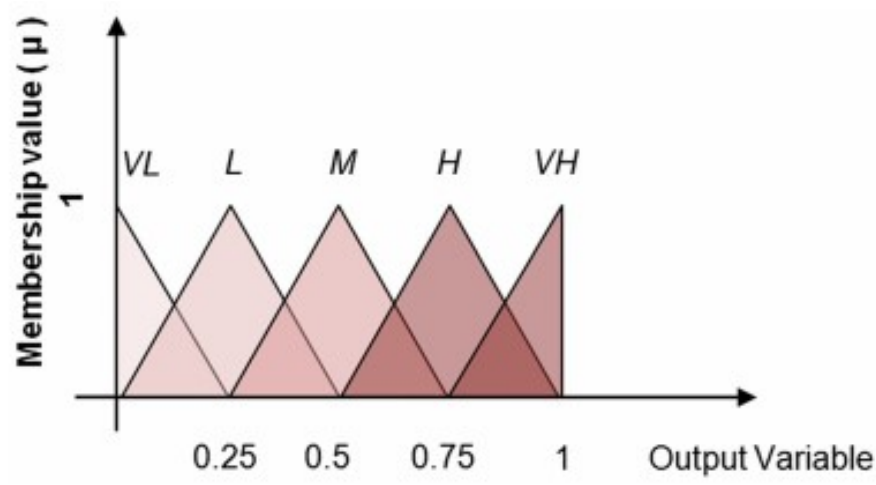

Figure 2: Triangular membership function [19]

$$
x^{*}=\frac{\sum_{i=1}^{N} x_{i} * \sum_{k=1}^{N} \mu_{A_{k}}\left(x_{i}\right)}{\sum_{i=1}^{N} \sum_{k=1}^{n} \mu_{A_{k}}\left(x_{i}\right)}
$$

Where $n$ stands for the sum total of fuzzy sets, $N$ is the sum total of fuzzy variables, and, $\mu_{A_{k}}\left(x_{i}\right)$ is the membership function for the k-th fuzzy set.

\section{Data analysis}

\subsection{Fuzzy cognitive map results}

As stated before, each edge, at least three linguistic terms are assigned to, even, for a few edges, four linguistic terms are assigned to.

A standard fuzzy set operation will be used, which is a standard union. Where,

$$
\mu_{A \cup B}(u)=\max \left\{\mu_{A}(u), \mu_{B}(u)\right\}
$$

To illustrate, there are the three linguistic terms assigned to the edge of $\mathrm{C} 22-\mathrm{C}$, they are: "LOW", "VERY LOW", and "VERY LOW".

$$
\begin{aligned}
& A 1=\frac{1}{2} *[(0.25-0)+(0-0)] * 1=0.125 \\
& A 2=\frac{1}{2} *[(0.5-0)+(0.25-0.25)] * 1=0.25 \\
& A 3=\frac{1}{2} *[(0.25-0)+(0-0)] * 1=0.125
\end{aligned}
$$

The center of area of the fuzzy set C1 is $\overline{x_{1}}=(0.25+0) / 2=0.125$, similarly, $\overline{x_{2}}=0.25$, $\overline{x_{3}}=0.125$. Now, the calculated defuzzified value $x^{*}=\frac{\left(A_{1} \overline{x_{1}}+A_{2} \overline{x_{2}}+A_{3} \overline{x_{3}}\right)}{A_{1}+A_{2}+A_{3}}=0.1875$.

A final version of the calculated fuzzy cognitive map is presented in Figure. 3. This FCM is drawn with software "Mental Modeler".

The following FCM weights are calculated based on the defuzzified values of the FCM. A summary of the calculation results is presented in Table 4. And, Table 5 provides the corresponding adjacency matrix of the FCM. This matrix can be used to describe the interrelations between the concept. 


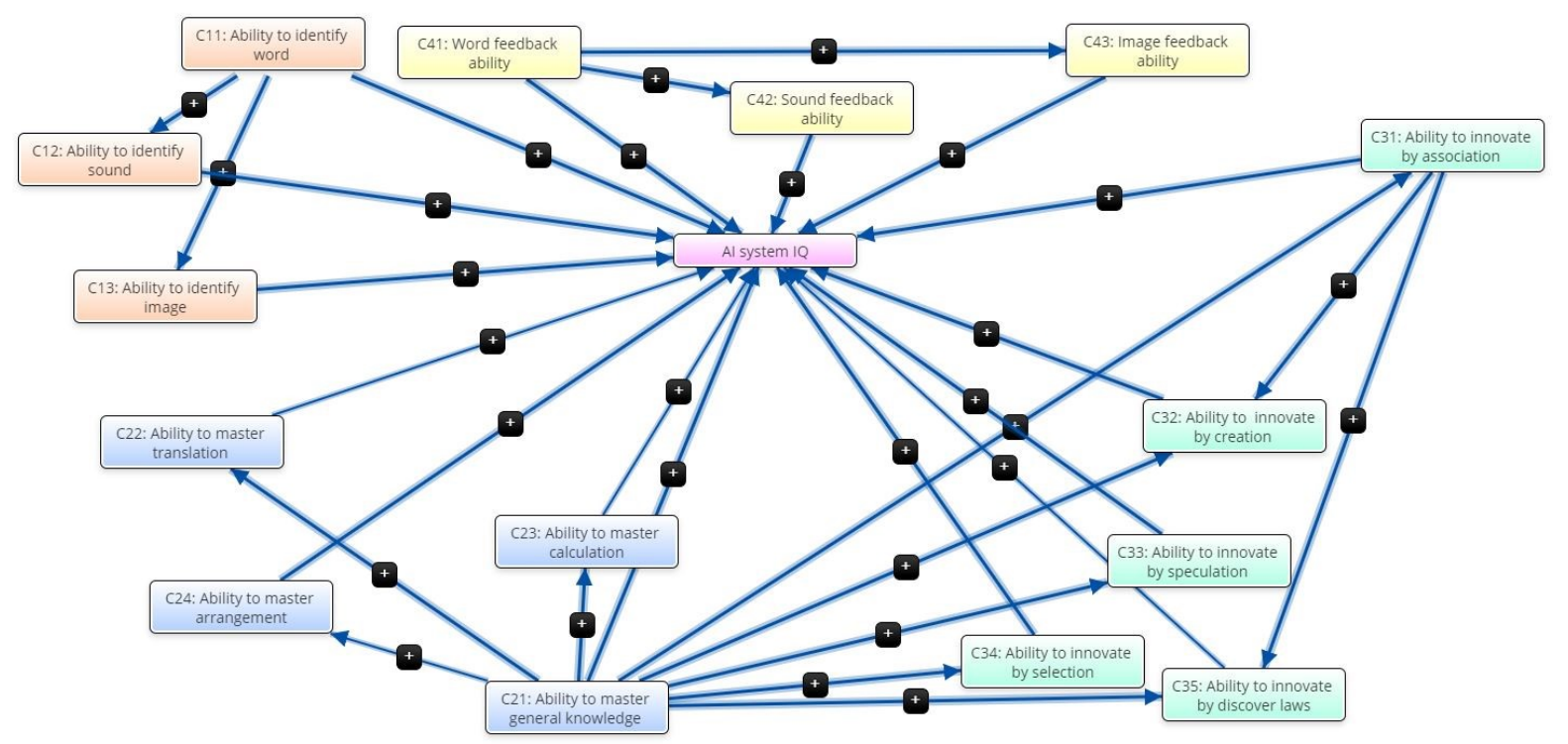

Figure 3: Fuzzy Cognitive Map with positive/negative sign to edges.

Table 4: Edge with its calculated weights

\begin{tabular}{|c|c|c|c|}
\hline EDGE OF FCM & DEFUZZIFIED VALUE & FCM WEIGHT & DELPHI WEIGHT \\
\hline $\mathrm{C} 11-\mathrm{C}$ & 0.5 & $6.0373 \%$ & $3 \%$ \\
\hline $\mathrm{C} 12-\mathrm{C}$ & 0.6786 & $8.1939 \%$ & $3 \%$ \\
\hline $\mathrm{C} 13-\mathrm{C}$ & 0.5833 & $7.0432 \%$ & $4 \%$ \\
\hline $\mathrm{C} 21-\mathrm{C}$ & 0.5625 & $6.792 \%$ & $6 \%$ \\
\hline $\mathrm{C} 22-\mathrm{C}$ & 0.1875 & $2.264 \%$ & $3 \%$ \\
\hline $\mathrm{C} 23-\mathrm{C}$ & 0.45 & $5.4336 \%$ & $6 \%$ \\
\hline $\mathrm{C} 24-\mathrm{C}$ & 0.5 & $6.0373 \%$ & $5 \%$ \\
\hline $\mathrm{C} 31-\mathrm{C}$ & 0.6071 & $7.3305 \%$ & $12 \%$ \\
\hline $\mathrm{C} 32-\mathrm{C}$ & 0.7961 & $9.6126 \%$ & $12 \%$ \\
\hline $\mathrm{C} 33-\mathrm{C}$ & 0.8125 & $9.8107 \%$ & $12 \%$ \\
\hline $\mathrm{C} 34-\mathrm{C}$ & 0.5 & $6.0373 \%$ & $12 \%$ \\
\hline $\mathrm{C} 35-\mathrm{C}$ & 0.4167 & $5.0315 \%$ & $12 \%$ \\
\hline $\mathrm{C} 41-\mathrm{C}$ & 0.5 & $6.0373 \%$ & $3 \%$ \\
\hline $\mathrm{C} 42-\mathrm{C}$ & 0.5 & $6.0373 \%$ & $3 \%$ \\
\hline $\mathrm{C} 43-\mathrm{C}$ & 0.6875 & $7.3305 \%$ & $12 \%$ \\
\hline $\mathrm{C} 11-\mathrm{C} 12$ & 0.6525 & $\mathrm{~N} / \mathrm{A}$ & $0 \%$ \\
\hline $\mathrm{C} 11-\mathrm{C} 13$ & 0.5 & $\mathrm{~N} / \mathrm{A}$ & $0 \%$ \\
\hline $\mathrm{C} 21-\mathrm{C} 22$ & 0.5625 & $\mathrm{~N} / \mathrm{A}$ & $0 \%$ \\
\hline $\mathrm{C} 21-\mathrm{C} 23$ & 0.5 & $\mathrm{~N} / \mathrm{A}$ & $0 \%$ \\
\hline $\mathrm{C} 21-\mathrm{C} 24$ & 0.4 & $\mathrm{~N} / \mathrm{A}$ & $0 \%$ \\
\hline $\mathrm{C} 21-\mathrm{C} 31$ & 0.7015 & $\mathrm{~N} / \mathrm{A}$ & $0 \%$ \\
\hline $\mathrm{C} 21-\mathrm{C} 32$ & 0.6071 & $\mathrm{~N} / \mathrm{A}$ & $0 \%$ \\
\hline $\mathrm{C} 21-\mathrm{C} 33$ & 0.6875 & $\mathrm{~N} / \mathrm{A}$ & $0 \%$ \\
\hline $\mathrm{C} 21-\mathrm{C} 34$ & 0.6071 & $\mathrm{~N} / \mathrm{A}$ & $0 \%$ \\
\hline $\mathrm{C} 21-\mathrm{C} 35$ & 0.6875 & & $0 \%$ \\
\hline & & & \\
\hline
\end{tabular}




\begin{tabular}{|c|c|c|c|}
\hline C41-C42 & 0.6525 & $\mathrm{~N} / \mathrm{A}$ & $0 \%$ \\
\hline C41-C43 & 0.5 & $\mathrm{~N} / \mathrm{A}$ & $0 \%$ \\
\hline C31-C35 & 0.6875 & $\mathrm{~N} / \mathrm{A}$ & $0 \%$ \\
\hline C31-C32 & 0.6071 & $\mathrm{~N} / \mathrm{A}$ & $0 \%$ \\
\hline
\end{tabular}

Table 5: Adjacency matrix collected from the Fuzzy Cognitive Map

\begin{tabular}{|c|c|c|c|c|c|c|c|c|c|c|c|c|c|c|c|c|}
\hline & C11 & C12 & C13 & C21 & C22 & $\mathrm{C} 23$ & C24 & C31 & C32 & C33 & C34 & C35 & C41 & $\mathrm{C} 42$ & $\mathrm{C} 43$ & $\begin{array}{l}\text { AI } \\
\text { sys- } \\
\text { tem } \\
\text { IQ }\end{array}$ \\
\hline C11 & 0 & 0.65 & 0.5 & 0 & 0 & 0 & 0 & 0 & 0 & 0 & 0 & 0 & 0 & 0 & 0 & 0.5 \\
\hline C11 & 0 & 0.65 & 0.5 & 0 & 0 & 0 & 0 & 0 & 0 & 0 & 0 & 0 & 0 & 0 & 0 & 0.5 \\
\hline C12 & 0 & 0 & 0 & 0 & 0 & 0 & 0 & 0 & 0 & 0 & 0 & 0 & 0 & 0 & 0 & 0.68 \\
\hline C13 & 0 & 0 & 0 & 0 & 0 & 0 & 0 & 0 & 0 & 0 & 0 & 0 & 0 & 0 & 0 & 0.58 \\
\hline $\mathrm{C} 21$ & 0 & 0 & 0 & 0 & 0.56 & 0.5 & 0.4 & 0.7 & 0.61 & 0.69 & 0.61 & 0.69 & 0 & 0 & 0 & 0.56 \\
\hline C22 & 0 & 0 & 0 & 0 & 0 & 0 & 0 & 0 & 0 & 0 & 0 & 0 & 0 & 0 & 0 & 0.19 \\
\hline $\mathrm{C} 23$ & 0 & 0 & 0 & 0 & 0 & 0 & 0 & 0 & 0 & 0 & 0 & 0 & 0 & 0 & 0 & 0.45 \\
\hline C24 & 0 & 0 & 0 & 0 & 0 & 0 & 0 & 0 & 0 & 0 & 0 & 0 & 0 & 0 & 0 & 0.5 \\
\hline C31 & 0 & 0 & 0 & 0 & 0 & 0 & 0 & 0 & 0.61 & 0 & 0 & 0.69 & 0 & 0 & 0 & 0.61 \\
\hline C32 & 0 & 0 & 0 & 0 & 0 & 0 & 0 & 0 & 0 & 0 & 0 & 0 & 0 & 0 & 0 & 0.8 \\
\hline C33 & 0 & 0 & 0 & 0 & 0 & 0 & 0 & 0 & 0 & 0 & 0 & 0 & 0 & 0 & 0 & 0.81 \\
\hline C34 & 0 & 0 & 0 & 0 & 0 & 0 & 0 & 0 & 0 & 0 & 0 & 0 & 0 & 0 & 0 & 0.5 \\
\hline C35 & 0 & 0 & 0 & 0 & 0 & 0 & 0 & 0 & 0 & 0 & 0 & 0 & 0 & 0 & 0 & 0.42 \\
\hline C41 & 0 & 0 & 0 & 0 & 0 & 0 & 0 & 0 & 0 & 0 & 0 & 0 & 0 & 0.65 & 0.5 & 0.5 \\
\hline C42 & 0 & 0 & 0 & 0 & 0 & 0 & 0 & 0 & 0 & 0 & 0 & 0 & 0 & 0 & 0 & 0.5 \\
\hline C43 & 0 & 0 & 0 & 0 & 0 & 0 & 0 & 0 & 0 & 0 & 0 & 0 & 0 & 0 & 0 & 0.69 \\
\hline $\begin{array}{l}\text { AI } \\
\text { sys- } \\
\text { tem } \\
\text { IQ }\end{array}$ & 0 & 0 & 0 & 0 & 0 & 0 & 0 & 0 & 0 & 0 & 0 & 0 & 0 & 0 & 0 & 0 \\
\hline
\end{tabular}

\subsection{FCM steady-state analysis}

A general descriptive summary about this FCM is shown in Table 6. The connection and component number is not extremely high. All the components can be categorized into the four groups. All the connections are supported by literature references. There are some interdependencies between the components in the same group. Also, there are some interconnections between components of different groups.

Figure. 3, which is the merged FCM, shows the density changed to 0.121 while the average connections per component increased to 1.8125 . Hierarchy Index is another complexity measurement of FCM. Hierarchy Index is answerable to all the concepts' out-degree in an FCM of N components [26]. Below is the equation of Hierarchy Index.

$$
h=\frac{12}{(N-1) N(N+1)} \sum_{1}^{N}\left[\frac{o d(v i)-\left(\sum o d(v i)\right)}{N}\right]^{2}
$$

Where $N$ is the total number of components. And, od(vi) is the row sum of absolute values 
Table 6: General FCM statistics

\begin{tabular}{|l|l|}
\hline FCM PROPERTIES & VALUE \\
\hline Total components & 16 \\
\hline Total connections & 29 \\
\hline Density & 0.121 \\
\hline Connections per Component & 1.8125 \\
\hline No. of driver components & 3 \\
\hline No. of receiver components & 1 \\
\hline No. of ordinary components & 12 \\
\hline Complexity score & 0.3333 \\
\hline
\end{tabular}

of a variable in the FCM adjacency matrix.

If $h$ is close to 1 , the FCM is supposed to be completely dominant (hierarchical). If $h$ is close to 0 , the FCM is supposed to be completely adaptated eco-strategies (democratic) [24]. This FCM's hierarchy index is 0.326 , which means, the FCM is much more adaptable to component changes because of its high level of integration and dependence. Also, the in-degree and outdegree of these nodes makes the FCM more democratic, and its system's steady-state more resistant to the alterations of individual components.

The component with the highest centrality was the "AI SYSTEM IQ" with a high score of 8.29. Also, the top three central components directly affecting the "AI SYSTEM IQ" component was the following, in ascending order of their complexity: Ability to innovate by discover laws 1.799, Ability to innovate by association 2.609, and, Ability to master general knowledge 5.319. A higher value means greater importance of an individual concept or several concepts in the overall model.

Table 7: Characteristic, type of concepts, in degree, out degree, centrality and in the FCM

\begin{tabular}{|l|l|l|l|l|}
\hline CHARACTERISTIC & INDEGREE & OUTDEGREE & CENTRALITY & TYPE \\
\hline AI system IQ & 8.29 & 0 & 8.29 & receiver \\
\hline C11 & 0 & 1.65 & 1.65 & driver \\
\hline C12 & 0.65 & 0.68 & 1.33 & ordinary \\
\hline C13 & 0.5 & 0.58 & 1.08 & ordinary \\
\hline C21 & 0 & 5.319 & 5.319 & driver \\
\hline C22 & 0.56 & 0.19 & 0.75 & ordinary \\
\hline C23 & 0.5 & 0.45 & 0.95 & ordinary \\
\hline C24 & 0.4 & 0.5 & 0.9 & ordinary \\
\hline C31 & 0.7 & 1.909 & 2.609 & ordinary \\
\hline C32 & 1.22 & 0.8 & 2.02 & ordinary \\
\hline C33 & 0.69 & 0.81 & 1.5 & ordinary \\
\hline C34 & 0.61 & 0.5 & 1.109 & ordinary \\
\hline C35 & 1.38 & 0.42 & 1.799 & ordinary \\
\hline C41 & 0 & 1.65 & 1.65 & driver \\
\hline C42 & 0.65 & 0.5 & 1.15 & ordinary \\
\hline C43 & 0.5 & 0.69 & 1.19 & ordinary \\
\hline
\end{tabular}




\subsection{Dynamic scenario analysis of the AI system IQ}

\section{Worst and best-case scenario}

The above AI system IQ FCM (Figure 3) shows its complexity. This research also conducted dynamic case scenario analyses along with inference simulation.

To start the analysis, we initially apply the current FCM. Both the worst and best scenario will be examined. After that, some insightful results and conclusions can be made. Based on our knowledge, the worst scenario means all the driver concepts are equal to 0.1 . And, the best scenario means all the driver concepts are equal to 1 .

From figure 4, we observe that there is approximately $58 \%$ increase in the "AI system IQ" in the worst scenario while compared to the initial steady-state scenario as the benchmark. Respectively, the "Ability to innovate by discover laws" has an increase of $13 \%$, the "Ability of innovate by creation" has an increase of $11 \%$. All the other concepts have an increase between $4 \%$ and $8 \%$. The results also show that all concepts have a positive causality. Furthermore, all of the slight increases for all the ordinary concepts are related to the small increase of driver concepts.

Alternatively, all the driver concepts can be set as primarily affecting the FCM's ordinary concepts if all the values are set up with 1. From figure 5, we found that the "AI system IQ" in the best scenario while compared to the initial steady-state scenario as the benchmark, has a $100 \%$ increase. Similarly, the "Ability of innovate by creation" has an increase of $80 \%$, and the "Ability to innovate by discover laws" has an increase of 75\%. All the other concepts have an increase between $38 \%$ and $60 \%$. This result also supports the conclusion of positive causality. Based on the results, the "Ability of innovate by creation" and "Ability to innovate by discover laws" has the most significant relevance impact.
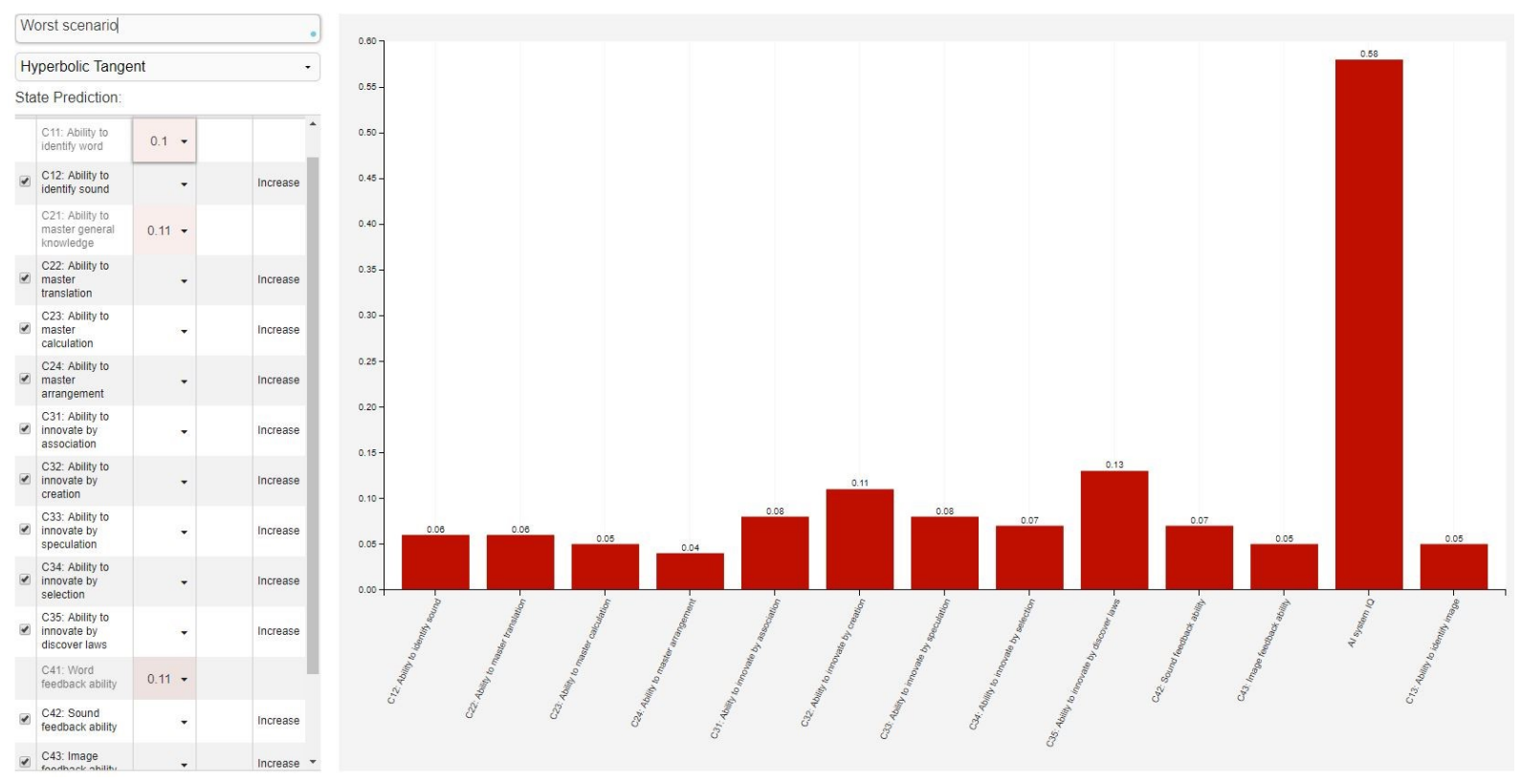

Figure 4: The driver concept effects for the worst scenario

\section{FCM inference simulation}

Based on the corresponding adjacency matrix (Table 5), there are some interrelations between concepts of this FCM. The value $A_{i}$ of $C_{i}$ is computed at each simulation step and it 


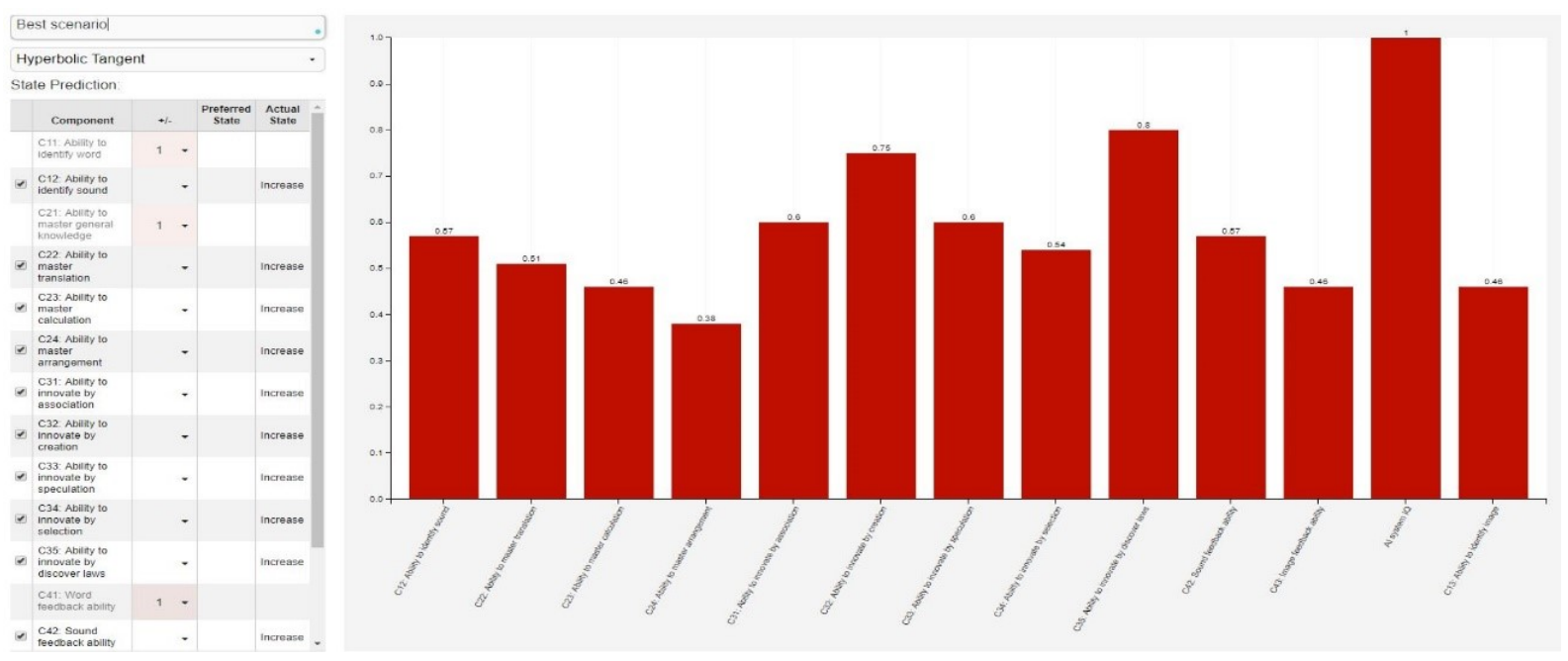

Figure 5: The driver concept effects for the best scenario

basically infers the influence of all other concepts $C_{j}$ to $C_{i}$. This research selected Standard Kosko's activation rule inference method, below is the activation function:

$$
A_{t}(K+1)=f\left\{\sum_{j=1, j \neq i}^{N} W_{j i} * A_{j}(k)\right\}
$$

Also, the threshold function uses the sigmoid function, which shown as:

$$
f(x)=\frac{1}{1+e^{-\lambda x}}
$$

Where $x$ is the value $A_{i}(K)$ at the equilibrium point, and $\lambda$ is a real positive number $(\lambda>$ 0 ) that determines the steepness of the continuous function $f$. Using sigmoid threshold ensure that the activation value belongs to the interval $[0,1]$.

When running the simulation, all the concepts were assigned an initial value of 0 . After a few simulation steps, all the values were expected to be convergence status. Theoretically, after reaching the equilibrium end states, larger activation value means playing a more important role in this FCM. All the driver and ordinary concepts were used for the simulation task. Figure 6 shows the corresponding concept activation levels per each iteration with all 18 concepts ranging from 0 to 1 . Table 8 gives us the inference concept values. All the inference simulations were run through "FCM Expert" software in this research.

Based on the plotter and the table results illustrated by the inference simulation process, it is easy to confirm that the top two critical roles are "C32: Ability to innovate by creation" and "C35: Ability to innovate by discover laws".

\section{Summary and conclusion}

In 2015, Liu et al. tested the selected 100 AI system based search engines IQ based on the Delphi weight approach [4]. This research article compares the new weight calculated through FCM approach to its original subjective approach and two other approaches while using the same data set as the input. Mean Square Error (MSE) is used here as a performance indicator, 
Modeling of Characteristics on Artificial Intelligence IQ Test:

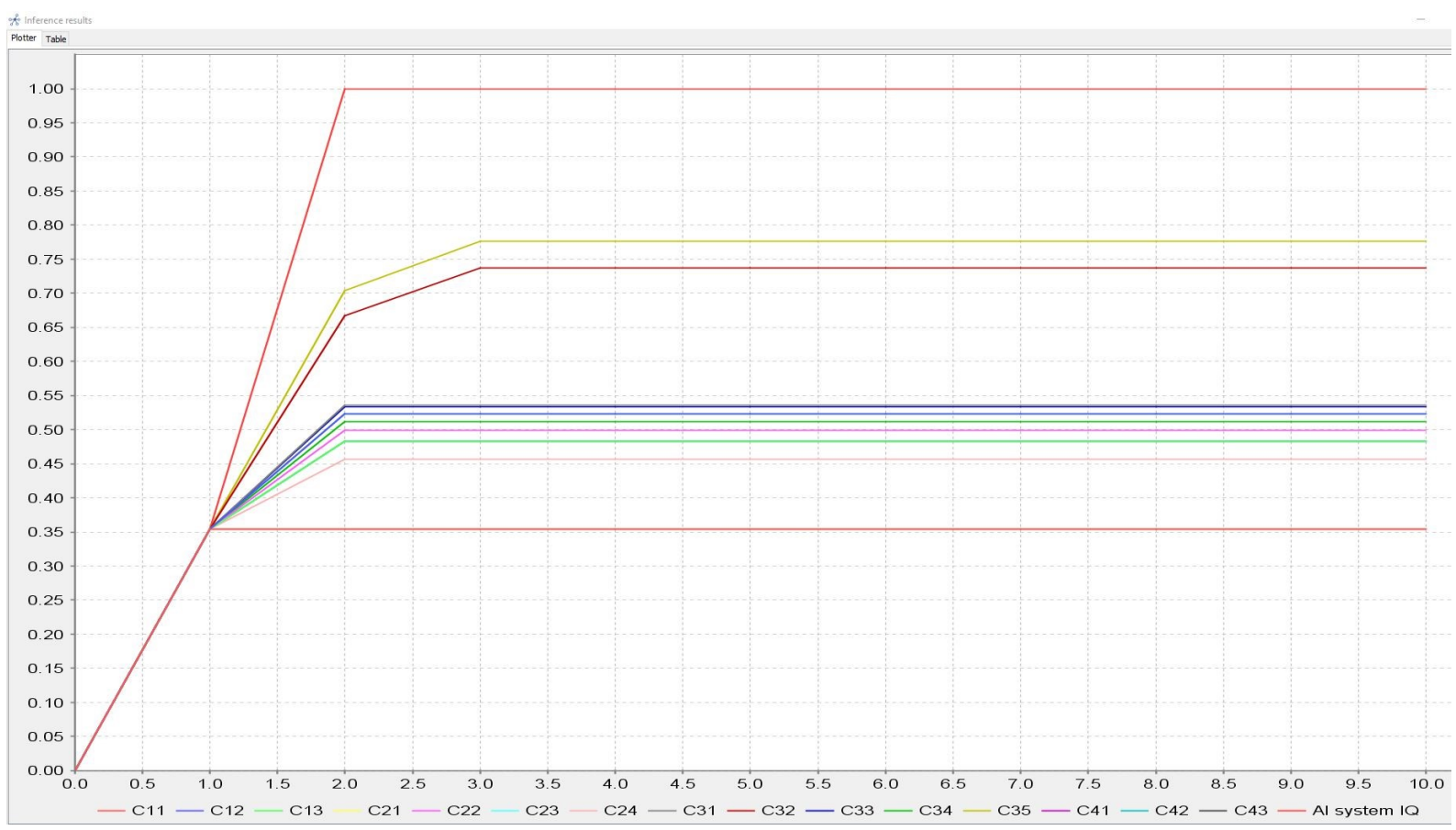

Figure 6: Simulation Activation level values per each iteration

Table 8: Inference concepts values

\begin{tabular}{|l|l|l|l|l|l|l|l|l|l|l|l|l|l|l|l|l|}
\hline Step & C11 & C12 & C13 & C21 & C22 & C23 & C24 & C31 & C32 & C33 & C34 & C35 & C41 & C42 & C43 & $\begin{array}{l}\text { AI } \\
\text { sys- } \\
\text { tem } \\
\text { IQ }\end{array}$ \\
\hline 0 & 0 & 0 & 0 & 0 & 0 & 0 & 0 & 0 & 0 & 0 & 0 & 0 & 0 & 0 & 0 & 0 \\
\hline 1 & 0.354 & 0.354 & 0.354 & 0.354 & 0.354 & 0.354 & 0.354 & 0.354 & 0.354 & 0.354 & 0.354 & 0.354 & 0.354 & 0.354 & 0.354 & 0.354 \\
\hline 2 & 0.354 & 0.522 & 0.482 & 0.354 & 0.498 & 0.482 & 0.456 & 0.536 & 0.667 & 0.533 & 0.512 & 0.704 & 0.354 & 0.522 & 0.482 & 0.999 \\
\hline $3-8$ & 0.354 & 0.522 & 0.482 & 0.354 & 0.498 & 0.482 & 0.456 & 0.536 & 0.736 & 0.533 & 0.512 & 0.776 & 0.354 & 0.522 & 0.482 & 1 \\
\hline 9 & 0.354 & 0.522 & 0.482 & 0.354 & 0.498 & 0.482 & 0.456 & 0.536 & 0.736 & 0.533 & 0.512 & 0.776 & 0.354 & 0.522 & 0.482 & 1 \\
\hline 10 & 0.354 & 0.522 & 0.482 & 0.354 & 0.498 & 0.482 & 0.456 & 0.536 & 0.736 & 0.533 & 0.512 & 0.776 & 0.354 & 0.522 & 0.482 & 1 \\
\hline
\end{tabular}

its equation can be found as below:

$$
M S E=\frac{1}{N} \sum_{i}^{N}\left(y_{i}-\hat{y}_{i}\right)^{2}
$$

Table 9 presents the MSE value for each approach. Dichotomous and polytomous [21] are two other old school methods. For the purpose of choosing the best approach, MSE works as a prediction error indicator here. It is to say, lowest MSE value means less prediction error. Based on MSE values, it is easy to say FCM approach is among the four approaches.

Table 9: MSE results for four methods

\begin{tabular}{|l|l|}
\hline APPROACH & MSE \\
\hline Delphi Weight & 37.63363 \\
\hline Polytomous & 49.51347 \\
\hline Dichotomous & 31.23294 \\
\hline FCM approach & 19.16389 \\
\hline
\end{tabular}


This article presents a new method to assign weights for the edges of the FCM. The MSE criteria show the FCM approach has a better performance than the other three approaches.

According to the proposed FCM, it is easy to conclude that the AI system IQ score is not just determined by linear concept dependence combinations. Actually, it is a nonlinear one, because there are a few significant relationships between concepts.

The dynamic scenario analysis has shown that the driver concepts together have a significant positive impact on the AI system IQ and other related concepts. Due to the reference limitation, we didn't find sufficient negative relationships exist in this FCM.

Based on the inference simulation results, it is coherent to reveal that the higher importance of "C32: Ability to innovate by creation" and "C35: Ability to innovate by discover laws" and other concepts. The simulation after seven iterations illustrates that all the concepts adjusted to a convergence status, which means changing values of concepts, could affect but will be reaching an equilibrium end state.

There are also some limitations in the present study. Different literature resources may use different words, which are synonyms of the concepts. For example, some paper may use "verbal" to replace "sound". Another is the low quality of the original data. The original test result data set is highly distributed left. Which means the MSE performance indicator may have a bias. Also, there may be unidentified interrelationships between the concepts, which needs further literature investigation. Furthermore, This FCM used the methodology of fuzzy membership function and other techniques to capture the nature of the AI system IQ test, there is a lot of room for improvement in identifying the characteristics. For example, more sub-characteristics can be added into future FCM, even the most determined concepts affecting the AI system IQ score can be identified. Another thing that can be improved is the relationship between concepts, currently, most of the relationship edges are one-way directions, maybe some relationship can be a two-way direction. For example, AI system IQ may also have an impact to C23. After all the possible improvements, an advanced FCM dynamic scenario may be used to analyze and re-design the FCM to reduce some not significant edges.

\section{Data availability}

The data used in the research paper are available from the corresponding author upon request.

\section{Conflict of interest}

The authors declare that there are no conflicts of interest regarding the publication of this paper.

\section{Funding statement}

This research is supported in part by a grant from Chinese Academy of Sciences (\#460806-0009). It is also supported by the Graduate Research and Creative Activity (GRACA) (\#42-1209-9116) grant of the University of Nebraska at Omaha, and the grants of the National Science Foundation of China (No.7193000078, No.91546201).

\section{Acknowledgment}

We are using this opportunity to express our gratitude to Shihang Li and Joel McMaken from University of Nebraska at Omaha. We are thankful for their aspiring writing skill guidance, invaluable constructive advice during this research paper. 


\section{Bibliography}

[1] Afuah, A.; Afuah, A. (2003). Innovation management: strategies, implementation and profits, 2003.

[2] Agrawal, R.; Mannila, H.; Srikant, R.; Toivonen, H.; Verkamo, A. I. (1996). Fast discovery of association rules. Advances in knowledge discovery and data mining, 12(1), 307-328, 1996.

[3] Alexander, P. A.; Jetton, T. L.; Kulikowich, J. M. (1995). Interrelationship of knowledge, interest, and recall: Assessing a model of domain learning, Journal of educational psychology, 87(4), 559, 1995.

[4] Askew, M. (1998). Teaching Primary Mathematics: A guide for newly qualified \& student teachers. Hodder \& Stoughton, 1998.

[5] Baroody, A. J. (1999). Children's relational knowledge of addition and subtraction, Cognition and Instruction, 17(2), 137-175, 1999.

[6] Bereiter, C.; Scardamalia, M. (1989). Intentional learning as a goal of instruction. Knowing, learning, and instruction: Essays in honor of Robert Glaser, 361-392, 1989.

[7] Bostic, K. (2013). Nuance confirms its voice technology is behind Apple's Siri, AppleInsider, 2013.

[8] Chen, G. S.; Jheng, Y.; Liu, H.; Chen, S. (2007). A novel scoring method for stroke order based on choquet integral with fuzzy measure, Proceedings of the 7th Conference on 7th WSEAS international Conference on Applied Computer Science, 7, 82-87, 2007.

[9] Collombat, I. (2006). General knowledge: A basic translation problem solving Tool. Translation Studies in the new Millennium, Bilkent University, 2006.

[10] Cowan, R.; Donlan, C.; Shepherd, D. L.; Cole-Fletcher, R., Saxton, M.; Hurry, J. (2011). Basic calculation proficiency and mathematics achievement in elementary school children. Journal of Educational Psychology, 103(4), 786, 2011.

[11] De Smedt, B.; Reynvoet, B.; Swillen, A.; Verschaffel, L.; Boets, B.; Ghesquiere, P. (2009). Basic number processing and difficulties in single-digit arithmetic: Evidence from VeloCardio-Facial Syndrome, Cortex, 45(2), 177-188, 2009.

[12] De Smedt, B.; Gilmore, C. K. (2011). Defective number module or impaired access? Numerical magnitude processing in first graders with mathematical difficulties, Journal of experimental child psychology, 108(2), 278-292, 2011.

[13] Delisle, J. (2003). Manuel d'initiation a la traduction professionnelle de l'anglais vers le francais La traduction raisonnee, 2e edition, University of Ottawa Press, 2003.

[14] Dzitac, I.; Filip, F. G.; Manolescu M.J. (2017). Fuzzy Logic Is Not Fuzzy: World-renowned Computer Scientist Lotfi A. Zadeh, International Journal of Computers Communications \& Control, 12(6), 748-789, 2017.

[15] Feigenson, L.; Dehaene, S.; Spelke, E. (2004). Core systems of number. Trends in cognitive sciences, 8(7), 307-314, 2004.

[16] Gopnik, A.; Meltzoff, A. N. (1984). Semantic and cognitive development in 15-to 21-monthold children, Journal of child language, 11(3), 495-513, 1984. 
[17] Hull, J. J. (1994). A database for handwritten text recognition research, IEEE Transactions on pattern analysis and machine intelligence, 16(5), 550-554, 1994.

[18] Klahr, D.; Dunbar, K. (1988). Dual space search during scientific reasoning. Cognitive science, 12(1), 1-48, 1988.

[19] Klir, G.; Yuan, B. (1995). Fuzzy sets and fuzzy logic , 4, New Jersey, Prentice Hall, 1995.

[20] Koperski, K.; Han, J. (1995). Discovery of spatial association rules in geographic information databases, International Symposium on Spatial Databases, Springer, Berlin, Heidelberg, 4766, 1995.

[21] Lewis-Beck, M.; Bryman, A. E.; Liao, T. F. (2003). The Sage encyclopedia of social science research methods, Sage Publications, 2003.

[22] Linnenbrink-Garcia, L.; Pugh, K. J.; Koskey, K. L.; Stewart, V. C. (2012). Developing conceptual understanding of natural selection: The role of interest, efficacy, and basic prior knowledge. The Journal of Experimental Education, 80(1), 45-68, 2012.

[23] Liu, F.; Shi, Y.; Wang, B. (2015). World search engine IQ test based on the internet IQ evaluation algorithms, International Journal of Information Technology \& Decision Making, 14(02), 221-237, 2015.

[24] Liu, F.; Zhang, Y.; Shi, Y.; Chen, Z.; Feng, X. (2018). Analyzing the Impact of Characteristics on Artificial Intelligence IQ Test: A Fuzzy Cognitive Map Approach, Procedia computer science, 139, 82-90, 2018.

[25] Luhn, H. P. (1958). The automatic creation of literature abstracts. IBM Journal of research and development, 2(2), 159-165, 1958.

[26] MacDonald, N. (1983). Trees and networks in biological models, 1983.

[27] Mago, V. K.; Morden, H. K.; Fritz, C.; Wu, T.; Namazi, S.; Geranmayeh, P.; Dabbaghian, V. (2013). Analyzing the impact of social factors on homelessness: a Fuzzy Cognitive Map approach. BMC medical informatics and decision making, 13(1), 94, 2013.

[28] Mandler, J. M.; Bauer, P. J. (1988). The cradle of categorization: Is the basic level basic?, Cognitive development, 3(3), 247-264, 1988.

[29] Miyake, N.; Norman, D. A. (1979). To ask a question, one must know enough to know what is not known, Journal of verbal learning and verbal behavior, 18(3), 357-364, 1979.

[30] Nation, K.; Snowling, M. J. (1998). Semantic processing and the development of wordrecognition skills: Evidence from children with reading comprehension difficulties. Journal of memory and language, 39(1), 85-101, 1998.

[31] Njoo, M.; De Jong, T. (1993). Exploratory learning with a computer simulation for control theory: Learning processes and instructional support. Journal of research in science teaching, 30(8), 821-844, 1993.

[32] Piatetsky-Shapiro, G. (1996). Advances in knowledge discovery and data mining (Vol. 21). U. M. Fayyad, P. Smyth, R. Uthurusamy (Eds.). Menlo Park: AAAI press, 1996.

[33] Poole, D. L.; Mackworth, A. K.; Goebel, R. (1998). Computational intelligence: a logical approach, 1, New York: Oxford University Press, 1998. 
[34] Qian, G.; Alvermann, D. (1995). Role of epistemological beliefs and learned helplessness in secondary school students' learning science concepts from text. Journal of educational psychology, 87(2), 282, 1995.

[35] Rugg, G.; McGeorge, P. (1997). The sorting techniques: a tutorial paper on card sorts, picture sorts and item sorts, Expert Systems, 14(2), 80-93, 1997.

[36] Rusell, S.; Norvig, P. (2003). Artificial intelligence: A modern approach. Prentice Hall Series in Artificial Intelligence, 1, 2003.

[37] Salmeron, J. L. (2012). Fuzzy Cognitive Maps for Artificial Emotions Forecasting , Applied Soft Computing. 12 (2), 3704-3710, 2012.

[38] Scardamalia, M.; Bereiter, C. (1992). Text-based and knowledge based questioning by children, Cognition and instruction, 9(3), 177-199, 1992.

[39] Stanovich, K. E.; Bauer, D. W. (1978). Experiments on the spelling-to-sound regularity effect in word recognition, Memory \& Cognition, 6(4), 410-415, 1978.

[40] Stanovich, K. E. (1991). Word recognition: Changing perspectives. Handbook of reading research, 2, 418-452, 1991.

[41] Talaya, A. E. (2008). Principios de marketing. Esic Editorial, 2008.

[42] Van Joolingen, W. (1998). Cognitive tools for discovery learning, 1998.

[43] Wang, K.; Babenko, B.; Belongie, S. (2011). End-to-end scene text recognition. 2011 International Conference on Computer Vision, IEEE, 1457-1464, 2011.

[44] Zhu, Y.; Tan, T.; Wang, Y. (2001). Font recognition based on global texture analysis. IEEE Transactions on pattern analysis and machine intelligence, 23(10), 1192-1200, 2001. 